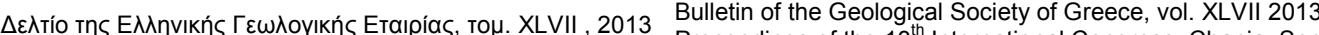
Proceedings of the $13^{\text {th }}$ International Congress, Chania Sept.

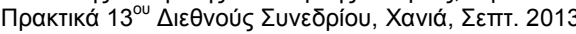
2013

\title{
CORRELATIONS BETWEEN MECHANICAL AND GEOMETRICAL PARAMETERS IN AGGREGATES: A TOOL FOR QUALITY ASSESSMENT AND CONTROL
}

\author{
Xirouchakis D. \\ GeoTerra Ltd, Geomechanics \& Quality Control Laboratory, 12 Anthrakorichon Street, 14235 \\ NeaIonia,dxirouch@gmail.com
}

\begin{abstract}
Correlations between mechanical and geometrical parameters in aggregates can be used as quality and performance prediction tools. I evaluated the following paramet er pairs: dry and wet resistance to wear $\left(M D_{E} \& M D_{S}\right)$, and resistance to fragmenta tion (LA); polishing resistance and abrasion ( $P S V-A A V)$; and flakiness and shape in dex (FI-SI). The data set comprises slags, sedimentary, igneous, and metamorphic $r$ ocks tested according to EN standard test methods. FI and SI are positively correlat ed $(r=0.83)$ and can be well described by the 1:1 line. Wet and dry resistance to we ar are strongly correlated $(r=0.98)$ with $M D_{E} \approx 2 \cdot M D_{S}$. Dry resistance to fragment ation $(L A)$ and wet resistance to wear $\left(M D_{E}\right)$ are well correlated $(r=0.81)$, and can be described with the equation $L A=4.95 \times M D_{E}^{0,61}\left(R^{2}=0.69\right)$. According to the PS $V-A A V$ correlation, aggregates are divided into two groups with contrasting behavi or. Limestones and slags $(r=-0.49$ to -0.69$)$ exhibit high polishing for high abrasi on resistance (high PSV-low AAV), whereas sandstones and mafic to intermediate $v$ olcanics ( $r=0.44$ to 0.39) exhibit high polishing for low abrasion resistance (high PSV-high AAV). Peridotites belong to either PSV-AAV group depending on the soft minerals.
\end{abstract}

Key words: aggregates, shape, wear, polishing, abrasion.

\section{Пєрí $\eta \Psi \psi \eta$}

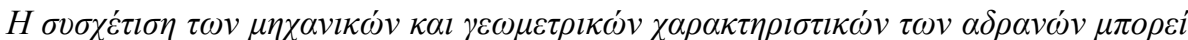

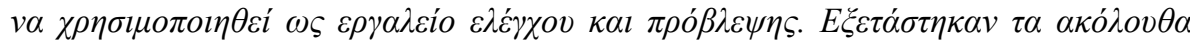

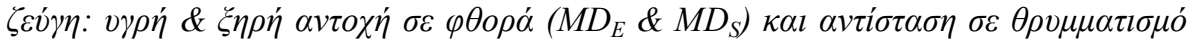

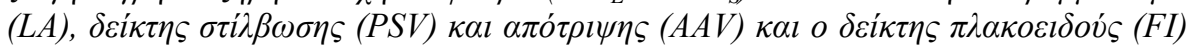

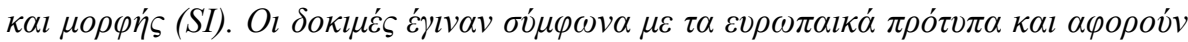

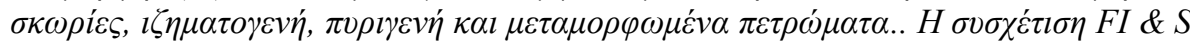

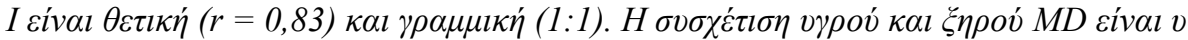

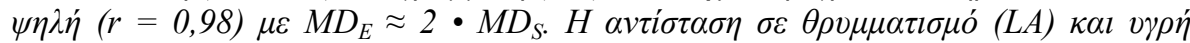

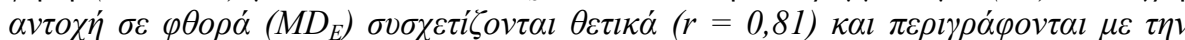

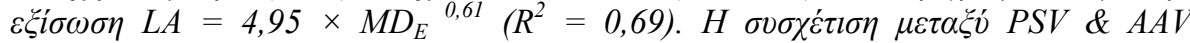

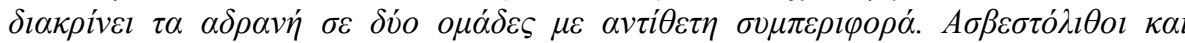

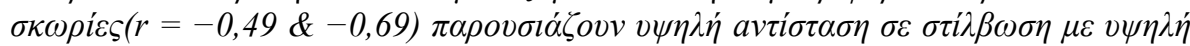

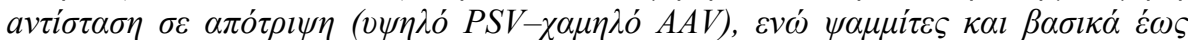

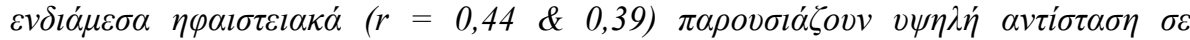

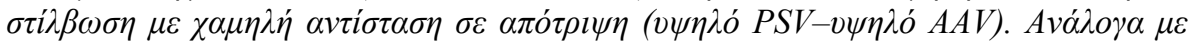

$\underline{\text { XLVII, No } 3-2069}$ 


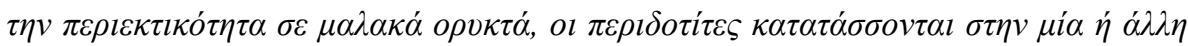

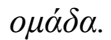

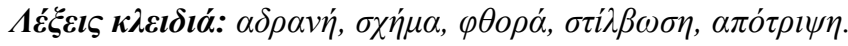

\section{Introduction}

According to the European Aggregates Association, approximately $90 \%$ of all aggregates produced in EU are from quarries (49\%) and pits (41\%). The rest are recycled aggregates, and marine and manufactured aggregates. The aggregates sector is the largest amongst the nonenergy extractive industries, directly and indirectly employing 250,000 people and representing a turnover of around $€ 20$ billion. Aggregates are a granular material typically used in construction (concrete and asphalt plants, new construction, and repairs), and the most common natural aggregates of mineral origin are sand, gravel and crushed rock. Market demand dictates production quantity and quality. The latter strongly depends on materials properties and processing technology.

Producers of aggregates face more than one set of materials performance requirements (e.g., grading, particle shape, surface texture, durability, abrasion resistance). Therefore, aggregate testing is critical to evaluate production quality and anticipated performance. In this study, I concentrated on pairs of parameters. Specifically, I looked at the correlation between parameters for particle shape, resistance to wear and fragmentation under dry and wet conditions, and resistance to polishing and abrasion. The goal was to critically evaluate the apparent or suspected correlations between them, and their potential as a quality control and prediction tool. I have not attempted to correlate materials properties and processing technology because of lack of relevant data. Nonetheless, this something that industry has been exploring (e.g., Magerowski, 2000).

\section{Materials and Methods}

For self-consistency, only data from tests performed according to EN standard methods by GeoTerra personnel or reported by others were considered. The data set comprises slags, igneous, metamorphic, and sedimentary rocks. The GeoTerra data base includes coarse aggregates (4/31.5) from sites either sampled once or multiple times between 2007 and 2012. Sampling was commonly performed by the same quarry employee at each site according to EN 932-1, and the same pool of laboratory technicians has performed the testing. Part of the GeoTerra data base in Tables 1, 2, and 3 was previously reported as ranges and averages along with mineralogy data (Xirouchakis and Theodoropoulos, 2009; Xirouchakis and Manolakou, 2011). The sources for the rest of data, which are not included in the tables, are: Reis Ferreira et al. (2010) and Sofilić et al. (2007) for EAF slags; Prapidis et al. (2005) for Fe and Pb slags; Thompson et al. (2004) for EAF \& BOF slags, sandstones, and mafic to intermediate crystalline volcanics (basalt-andesite, s.1.); Kalofotias et al. (2011) for limestones; Rigopoulos et al. (2006, 2008) and Pomonis et al. (2007) for mafic rocks; and Kossiari (2007), and Rigopoulos et al. (2012) for peridotites; and Lucieri et al. (2005) for limestones and mafic to intermediate crystalline volcanics (basalt-andesite, s.1.) from Tuscany, Italy.

Construction Materials Testing (CMT) laboratories rely on the Flakiness Index (FI) and Shape Index (SI) for evaluating particle shape. The FI (EN 933-3) and SI (EN 933-4) values represent mass percentages of flaky and elongate grains. Resistance to wear under wet and dry conditions is assessed by the Micro-Deval method (EN 1097-1) and expressed as $\mathrm{MD}_{\mathrm{E}}$ and $\mathrm{MD}_{\mathrm{S}}$, respectively. Resistance to fragmentation (EN 1097-2) is performed under dry conditions and is reported as the LA value. The resistance of coarse aggregates to polishing and abrasion prior to use in road surfaces is assessed through the Polishing Stone and Abrasion method (EN 1097-8 \& Appendix A). Test procedures as well as precision statements are given in the standard test methods. The relative expanded uncertainty $\% \mathrm{U}(95 \%$ confidence level) for all non-GeoTerra data was estimated from the precision and accuracy statements in the standard test methods. For the GeoTerra data set, the

$\underline{\text { XLVII, No } 3-2070}$ 
relative expanded uncertainty is $5.1 \%, 2.0 \%, 5.1 \%, 8.0 \%, 6.7 \%, 0.6 \%$, and $5.7 \%$ for FI, SI, $\mathrm{MD}_{\mathrm{E}}$, $\mathrm{MD}_{\mathrm{S}}$, LA, PSV, and AAV, respectively. The relative expanded uncertainty is used to construct the error bars in Figures 1, 2, and 3. To evaluate data variability for sites that were sampled over a period of years, which applies to many cases in the GeoTerra data base, I opted to look at the ratio of single-year to multiple-year standard deviation $\left(s_{\text {single-year }} / s_{\text {multiple-year }}\right)$ or average $\left(\mu_{\text {single- }}\right.$ year $\left./ \mu_{\text {multiple-year }}\right)$ as proxy for within-group to between-group variability. For low-variability data, the abovementioned ratios will be unity or close to unity. Considering that sampling and testing procedures are executed according to standard test methods and thus contribute little to variability, mineral and rock properties are the likely source for the data variability and correlations for samesource, low-variability data.

\section{Results and Discussion}

\subsection{FI versus SI}

Particle shape affects packing and mechanical stability of mixtures with and without binder as well as road surface properties (e.g., Janoo 1998; Janoo and Korhonen 1999; Naidu and Adisheshu 2011). Generally, a grain is classified as flaky if the width-thickness ratio is $>2.0$, elongated if the length-thickness ratio is $>2.5$, and cubic if the width-thickness ratio is $<2.0$ and the lengththickness ratio is $<2.5$.

According to the SI test, the grains are divided into cubical and noncubical, where the noncubical grains have a length-thickness ratio greater than 3, and SI represents the ratio of the mass of noncubical grains to the total mass of grains. FI distinguishes particles to flaky and nonflaky and is the ratio of the mass of flaky grains to the total mass of grains. Uthus et al. (2005) estimated that cubic and cubic rounded grains correspond to SI values of 0.083 and 0.056 and FI values of 10.99 and 8.08, whereas flaky and flaky rounded grains have SI values of 55.5 and 63.3 and FI values of 12.42 and 20.34, respectively. Hann (2009) experimentally determined the relation between SI and shape factor $\mathrm{F}$, on the basis of which, it appears that spherical and cubical grains with $\mathrm{F}$ between 1 and 0.785 correspond to SI between 4 and 20 .

The FI and SI values for EAF slags, limestones, and igneous rocks are listed in Table 1 and shown in Figure 1. Both indices are positively correlated regardless of rock type, site, or region with a correlation coefficient of 0.83 . The average $\mathrm{S}_{\text {single-year }} / \mathrm{s}_{\text {multiple-year }}$ for FI and SI is $1.0 \pm 0.1$ and $0.9 \pm$ 0.1 , respectively. For comparison, the average $\mu_{\text {single-year }} / \mu_{\text {multiple-year }}$ for FI and SI is $1.0 \pm 0.1$ and $1.0 \pm 0.1$, correspondingly.

Table 1 - Flakiness Index (FI) and Shape Index (SI) for slags \& volcanics.

\begin{tabular}{|c|c|c|c|c|c|}
\hline$F I$ & $S I$ & Comments & $F I$ & $S I$ & Comments \\
\hline 4 & 5 & EAF slag & 4 & 3 & EAF slag \\
\hline 5 & 6 & “ & 5 & 8 & “ \\
\hline 7 & 8 & “ & 4 & 4 & “" \\
\hline 10 & 9 & “ & 4 & 2 & “ \\
\hline 6 & 7 & “" & 5 & 3 & “ \\
\hline 5 & 7 & “" & 5 & 3 & “ \\
\hline 7 & 8 & “" & 6 & 3 & “ \\
\hline 4 & 4 & “" & 3 & 5 & “ \\
\hline 2 & 1 & “ & 2 & 3 & “ \\
\hline 5 & 4 & “" & 5 & 2 & EAF slag \\
\hline 3 & 7 & “ & 4 & 1 & ، \\
\hline
\end{tabular}

$\underline{\text { XLVII, No } 3-2071}$ 


\begin{tabular}{|c|c|c|c|c|c|}
\hline$F I$ & $S I$ & Comments & $F I$ & $S I$ & Comments \\
\hline 3 & 4 & “ & 1 & 2 & “ \\
\hline 6 & 6 & “ & 6 & 9 & Trachyte \\
\hline 4 & 5 & “ & 5 & 9 & “ \\
\hline 2 & 2 & “ & 11 & 10 & “ \\
\hline 3 & 5 & “ & 9 & 9 & “ \\
\hline 3 & 2 & “ & 7 & 7 & “ \\
\hline
\end{tabular}

Table 1 continued - Flakiness Index (FI) and Shape Index (SI) for limestone aggregates.

\begin{tabular}{llllllll}
\hline $\boldsymbol{F I}$ & $\boldsymbol{S I}$ & $\boldsymbol{F I}$ & $\boldsymbol{S}$ & $\boldsymbol{F I}$ & $\boldsymbol{S} \boldsymbol{F}$ & $\boldsymbol{F I}$ & $\boldsymbol{S I}$ \\
\hline 9 & 10 & 12 & 12 & 7 & 6 & 8 & 11 \\
9 & 7 & 8 & 5 & 7 & 1 & 5 & 8 \\
8 & 12 & 5 & 8 & 10 & 6 & 10 & 16 \\
8 & 10 & 11 & 10 & 11 & 8 & 10 & 12 \\
8 & 13 & 9 & 11 & 8 & 6 & 4 & 13 \\
8 & 10 & 12 & 13 & 12 & 9 & 11 & 14 \\
13 & 13 & 12 & 3 & 11 & 10 & 6 & 14 \\
24 & 30 & 9 & 7 & 8 & 7 & 15 & 14 \\
24 & 22 & 9 & 7 & 13 & 10 & 10 & 9 \\
13 & 11 & 9 & 22 & 15 & 13 & 16 & 18 \\
15 & 11 & 11 & 14 & 19 & 11 & 12 & 13 \\
15 & 22 & 6 & 6 & 5 & 6 & 21 & 25 \\
19 & 21 & 11 & 22 & 19 & 15 & 13 & 11 \\
13 & 20 & 12 & 12 & 33 & 26 & 14 & 10 \\
21 & 16 & 14 & 20 & 8 & 6 & 7 & 8 \\
6 & 6 & 13 & 8 & 10 & 10 & 22 & 26 \\
9 & 10 & 6 & 4 & 6 & 10 & 23 & 31 \\
14 & 20 & 9 & 7 & 10 & 18 & 40 & 47 \\
22 & 29 & 5 & 9 & 12 & 16 & 12 & 9 \\
8 & 10 & 22 & 15 & 14 & 24 & 10 & 14 \\
10 & 10 & 5 & 4 & 17 & 15 & 11 & 13 \\
\hline
\end{tabular}

The data in Figure 1 can be equally well described by the $1: 1$ line or the equation $\mathrm{FI}=1.01 \times \mathrm{SI}$ $\left(\mathrm{R}^{2}=0.63\right)$. The dashed line in Figure 1 represents the equation $\mathrm{SI}=1.13 \times \mathrm{FI}+1.04$ that Péturrson et al. (2000) used to describe the FI and SI correlation in Icelandic basaltic aggregates. Bulevicius et al. (2011) reported strong correlation between FI and SI for dolomitic and granitic aggregates $(r=0.7)$ and fitted the data with the equation SI $=2.714+0.595 \times$ FI (dot-dashed line in Figure 1). Xirouchakis and Theodoropoulos (2009) reported an $r$ of 0.62 between FI and SI for limestone aggregates and little to weak positive correlation between FI and LA $(r=0.10)$, FI and $\mathrm{MD}_{\mathrm{E}}(\mathrm{r}=0.09)$, SI and LA $(\mathrm{r}=0.15)$, and SI and $\mathrm{MD}_{\mathrm{E}}(\mathrm{r}=0.36)$. Bulevicius et al. (2011) found a positive, albeit strong, correlation between LA and FI $(r=0.64-0.73)$ and LA and SI $(0.62-0.76)$. 
In contrast, the data in Ioannou et al. (2010) suggest a moderate negative correlation between LA and FI $(\mathrm{r}=-0.55)$. However, this is opposite to what is intuitively expected and the data in Figure 1, which strongly suggest that hard materials will have low SIs and FIs and, therefore, higher mass percentages of nonflaky and cubical grains.

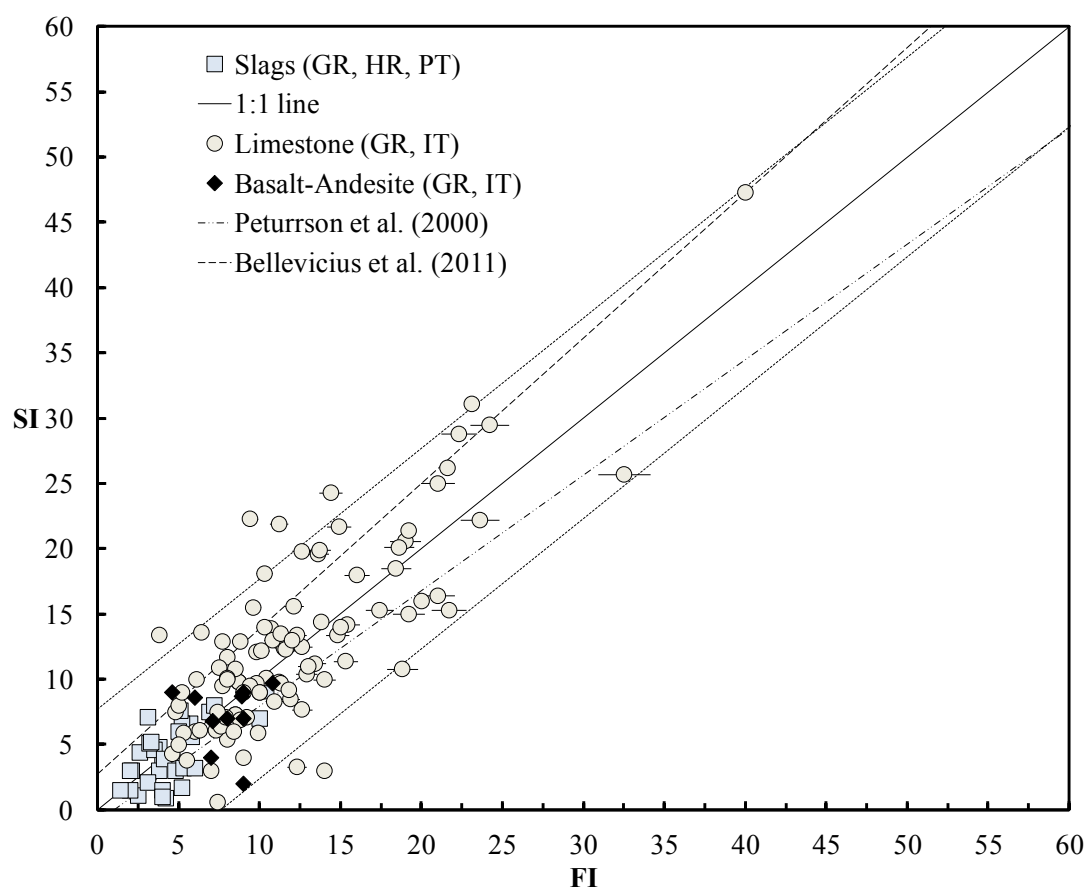

Figure 1 - FI vs SI values. GR: Greece; HR: Croatia; IT: Italy; and PT: Portugal. Dashed lines are $95 \%$ confidence limits for the $1: 1$ line.

\section{2. $\mathrm{MD}_{\mathrm{S}}$ versus $\mathrm{MD}_{\mathrm{E}}$ and $\mathrm{MD}_{\mathrm{E}}$ versus $\mathrm{LA}$}

Resistance to wear and fragmentation are used to evaluate materials suitability for construction and predict long-term performance; low $\mathrm{MD}_{\mathrm{S}}, \mathrm{MD}_{\mathrm{E}}$, and $\mathrm{LA}$ values typically characterize hard, mechanically strong materials. The data for resistance to wear under wet $\left(\mathrm{MD}_{\mathrm{E}}\right)$ and dry conditions $\left(\mathrm{MD}_{\mathrm{S}}\right)$, and resistance to fragmentation (LA) are given in Table 2. The $\mathrm{MD}_{\mathrm{S}}$ data set is less comprehensive than the rest but nonetheless useful. $\mathrm{MD}_{\mathrm{S}}$ and $\mathrm{MD}_{\mathrm{E}}$ are, unsurprisingly, strongly correlated $(\mathrm{r}=0.98)$ with $\mathrm{MD}_{\mathrm{S}}$ approximately half the corresponding $\mathrm{MD}_{\mathrm{E}}$ values regardless of rock type and $d_{i} / D_{i}$ fraction. Clearly, water enhances sample attrition. The $M_{E}$ and LA data are listed in Table 2 and shown in Figure 2. Dry resistance to fragmentation (LA) and wet resistance to wear $\left(\mathrm{MD}_{\mathrm{E}}\right)$ are positively correlated $(\mathrm{r}=0.81)$. In the GeoTerra data set and for the same sampling sites, the $\mathrm{s}_{\text {single-year }} / \mathrm{s}_{\text {multiple-year }}\left(\mu_{\text {single-year }} / \mu_{\text {multiple-year }}\right)$ ratio for LA is $0.9 \pm 0.1(1.5 \pm 0.2)$ and for $\mathrm{MD}_{\mathrm{E}}$ is $0.8 \pm 0.03(1.0 \pm 0.0)$.

Table 2 - Resistance to wear (MD) and fragmentation (LA).

\begin{tabular}{cccccccc}
\hline $\boldsymbol{d}_{\boldsymbol{i}} / \boldsymbol{D}_{\boldsymbol{i}}$ & $\boldsymbol{M D}_{\boldsymbol{E}}$ & $\boldsymbol{M D}_{\boldsymbol{S}}$ & $\boldsymbol{L} \boldsymbol{A}$ & Comments & $\boldsymbol{M D}_{\boldsymbol{E}}$ & $\boldsymbol{L} \boldsymbol{A}$ & Comments \\
\hline $10 / 14$ & 7 & & 18 & EAF slag & 8 & 14 & Basalt-Andesite \\
$10 / 14$ & 7 & 4 & 15 & “ & 10 & 13 & “ \\
$6.3 / 10$ & 7 & 4 & 15 & $\cdots$ & 12 & 12 & “ \\
$6.3 / 10$ & 8 & & 18 & “ & 8 & 13 & “
\end{tabular}




\begin{tabular}{|c|c|c|c|c|c|c|c|}
\hline$d_{i} / D_{i}$ & $M D_{E}$ & $M D_{S}$ & $L A$ & Comments & $M D_{E}$ & $L A$ & Comments \\
\hline $11.2 / 16$ & 7 & & 16 & “ & 8 & 12 & “ \\
\hline $6.3 / 10$ & 8 & & 21 & “ & 12 & 13 & " \\
\hline $10 / 14$ & 8 & & 19 & “ & 31 & 61 & Phyllite-Quartzite \\
\hline $11.2 / 16$ & 8 & & 15 & “ & & & \\
\hline $6.3 / 10$ & 7 & & 17 & “ & & & \\
\hline $11.2 / 16$ & 7 & & 16 & “ & & & \\
\hline $11.2 / 16$ & 9 & & 17 & “ & & & \\
\hline $8 / 11.2$ & 8 & & 15 & “ & & & \\
\hline $11.2 / 16$ & 7 & & 14 & “ & & & \\
\hline
\end{tabular}

Table 2 continued - Resistance to wear $\left(\mathrm{MD}_{\mathrm{E}}\right)$ and fragmentation (LA) for limestones.

\begin{tabular}{cccccc}
\hline $\boldsymbol{M D}_{\boldsymbol{E}}$ & $\boldsymbol{L} \boldsymbol{A}$ & $\boldsymbol{M D}_{\boldsymbol{E}}$ & $\boldsymbol{L A}$ & $\boldsymbol{M D}_{\boldsymbol{E}}$ & $\boldsymbol{L} \boldsymbol{A}$ \\
\hline 17 & 27 & 14 & 30 & 14 & 28 \\
25 & 26 & 16 & 31 & 15 & 25 \\
16 & 27 & 25 & 38 & 20 & 31 \\
24 & 26 & 25 & 31 & 15 & 25 \\
15 & 26 & 21 & 32 & 21 & 26 \\
15 & 26 & 20 & 35 & 15 & 28 \\
28 & 29 & 15 & 28 & 17 & 32 \\
27 & 29 & 10 & 26 & 17 & 31 \\
41 & 46 & 11 & 23 & 20 & 30 \\
33 & 42 & 10 & 27 & 17 & 37 \\
11 & 26 & 14 & 24 & 26 & 32 \\
11 & 25 & 15 & 30 & 26 & 33 \\
15 & 26 & 26 & 31 & 24 & 38 \\
10 & 25 & 28 & 36 & 30 & 46 \\
10 & 26 & 30 & 39 & 32 & 46 \\
9 & 21 & 34 & 43 & 25 & 38 \\
16 & 29 & 15 & 25 & 28 & 43 \\
18 & 30 & 15 & 39 & 32 & \\
24 & 29 & 26 & & & 31 \\
\hline 12 & & & 36 & & \\
\hline
\end{tabular}

Table 2 continued - Resistance to wear (MD) and fragmentation (LA) as a function of $d_{i} / D_{i}$.

\begin{tabular}{llllllllll}
\hline $\boldsymbol{d}_{\boldsymbol{i}} / \boldsymbol{D}_{\boldsymbol{i}}$ & $\boldsymbol{M D}_{\boldsymbol{E}}$ & $\boldsymbol{M D}_{\boldsymbol{S}}$ & $\boldsymbol{L A}$ & $\boldsymbol{d}_{\boldsymbol{i}} / \boldsymbol{D}_{\boldsymbol{i}}$ & $\boldsymbol{M D}_{\boldsymbol{E}}$ & $\boldsymbol{L} \boldsymbol{A}$ & $\boldsymbol{d}_{\boldsymbol{i}} / \boldsymbol{D}_{\boldsymbol{i}}$ & $\boldsymbol{M D}_{\boldsymbol{E}}$ & $\boldsymbol{L} \boldsymbol{A}$ \\
\hline $4 / 6.3$ & 10 & 6 & 22 & $11.2 / 16$ & 13 & 24 & $31.5 / 50$ & 18 & 35 \\
$10 / 14$ & 9 & & 26 & $31.5 / 50$ & 12 & 30 & $11.2 / 16$ & 20 & 27
\end{tabular}




\begin{tabular}{|c|c|c|c|c|c|c|c|c|c|}
\hline$d_{i} / D_{i}$ & $M D_{E}$ & $M D_{S}$ & $L A$ & $d_{i} / D_{i}$ & $M D_{E}$ & $L A$ & $d_{i} / D_{i}$ & $M D_{E}$ & $L A$ \\
\hline $8 / 11.2$ & 11 & & 26 & $31.5 / 50$ & 16 & 36 & $11.2 / 16$ & 16 & 26 \\
\hline $11.2 / 16$ & 28 & 12 & 31 & $10 / 14$ & 22 & 35 & $11.2 / 16$ & 21 & 26 \\
\hline $6.3 / 10$ & 30 & 16 & 34 & $8 / 11.2$ & 17 & 26 & $11.2 / 16$ & 24 & 21 \\
\hline $11.2 / 16$ & 30 & 14 & 35 & $8 / 11.2$ & 17 & 32 & $10 / 14$ & 16 & 29 \\
\hline $11.2 / 16$ & 30 & 15 & 35 & $11.2 / 16$ & 15 & 24 & $10 / 14$ & 16 & 30 \\
\hline $11.2 / 16$ & 31 & 14 & 38 & $11.2 / 16$ & 17 & 25 & $10 / 14$ & 16 & 26 \\
\hline $10 / 14$ & 32 & & 38 & $31.5 / 50$ & 19 & 31 & $31.5 / 50$ & 13 & 33 \\
\hline $11.2 / 16$ & 35 & 17 & 40 & $31.5 / 50$ & 14 & 27 & $31.5 / 50$ & 15 & 33 \\
\hline $11.2 / 16$ & 32 & & 42 & $31.5 / 50$ & 16 & 26 & $31.5 / 50$ & 16 & 36 \\
\hline $10 / 14$ & 29 & & 44 & $8 / 11.2$ & 22 & 30 & $31.5 / 50$ & 17 & 34 \\
\hline $10 / 14$ & 31 & & 38 & $4 / 6.3$ & 19 & 31 & $31 / 5 / 50$ & 18 & 35 \\
\hline $31.5 / 50$ & 26 & & 40 & $11.2 / 16$ & 22 & 34 & $11.2 / 16$ & 18 & 26 \\
\hline $31.5 / 50$ & 22 & & 45 & $11.2 / 16$ & 17 & 29 & $11.2 / 16$ & 20 & 28 \\
\hline $31.5 / 50$ & 24 & & 42 & $8 / 11.2$ & 22 & 32 & $31.5 / 50$ & 17 & 38 \\
\hline $31.5 / 50$ & 27 & & 44 & $8 / 11.2$ & 20 & 30 & $31.5 / 50$ & 14 & 37 \\
\hline $6.3 / 10$ & 15 & & 17 & $31.5 / 50$ & 18 & 33 & $31.5 / 50$ & 15 & 38 \\
\hline $11.2 / 16$ & 15 & & 28 & $31.5 / 50$ & 15 & 28 & & & \\
\hline $11.2 / 16$ & 17 & & 35 & $31.5 / 50$ & 18 & 29 & & & \\
\hline $11.2 / 16$ & 20 & & 28 & $31.5 / 50$ & 18 & 30 & & & \\
\hline
\end{tabular}

Dashed lines separate sampling sites. Test results at each site span a period of 3-4 years and represent limestone aggregates.

The $\mathrm{LA}-\mathrm{MD}_{\mathrm{E}}$ relation can be described with the equation $\mathrm{LA}=4.95 \times \mathrm{MD}_{\mathrm{E}}{ }^{0.61}\left(\mathrm{R}^{2}=0.69\right)$, which affords slightly better fitting than linear-type equations and better models the subtle nonlinearity in the $\mathrm{LA}-\mathrm{MD}_{\mathrm{E}}$ relation at low values for hard aggregates. The correlation of $\mathrm{MD}_{\mathrm{E}}$ and $\mathrm{LA}$ to the $\mathrm{d}_{\mathrm{i}} / \mathrm{D}_{\mathrm{i}}$ fraction is weak $\left(M \mathrm{DD}_{\mathrm{E}}-\mathrm{d}_{\mathrm{i}} / \mathrm{D}_{\mathrm{i}}, \mathrm{r}=0.18\right)$ to moderate $\left(\mathrm{LA}-\mathrm{d}_{\mathrm{i}} / \mathrm{D}_{\mathrm{i}} \mathrm{r}=0.40\right)$. Rigopoulos et al. $(2006,2008)$ and Pomonis et al. (2007) also found a positive correlation between $\mathrm{MD}_{\mathrm{E}}$ and LA and used linear and nonlinear equations to model the $\mathrm{LA}-\mathrm{MD}_{\mathrm{E}}$ relation. However, the proposed equations fail to describe the full extent of the data and only reproduce part of them within the 95\% envelope in Figure 2.

In general, there is neither much research in EU for the micro-Deval vs. LA correlation nor the limits associated with good long-term performance; probably because of the past lack of universal tests across EU. In contrast, Departments of Transportation (DOTs) and Research Centers (e.g., ICAR) in North America (CA \& USA) have adapted faster, even to a new test such a wet microDeval. Despite the differences between the EN and ASTM, or CAS, standard test methods, $\mathrm{MD}_{\mathrm{E}}$ and LA exhibit moderate to strong, positive correlation ( $\mathrm{r}=0.45-0.89$, Cooley et al., 2002; $\mathrm{r}=$ 0.80, Cuelho et al., 2007; $\mathrm{r}=0.89$, Richardson, 2009). Cuelho et al. (2008), after reviewing the US literature, also concluded that aggregates with good long-term performance have ASTM LA less than 40 and ASTM MDE less than 18. Despite the lack of similar research in Europe, using the limiting LA value of 30 for high-specification aggregates (Thompson et al. 2004) and the proposed equation, the corresponding limiting $\mathrm{MD}_{\mathrm{E}}$ value is 20 . The $\mathrm{LA}$ value of 30 and $\mathrm{MD}_{\mathrm{E}}$ value of 20 encompass hard materials such as slags and mafic to intermediate crystalline volcanics. 


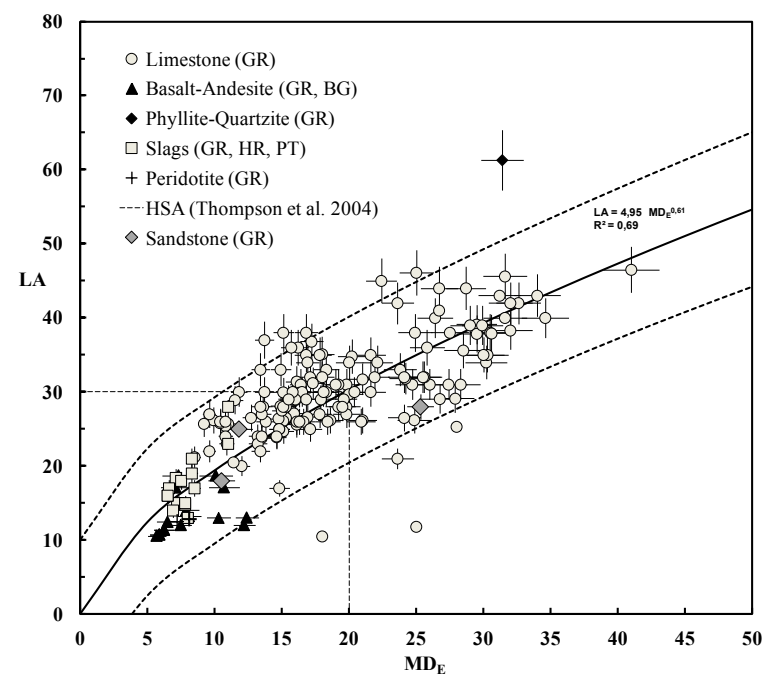

Figure $2-\mathrm{MD}_{\mathrm{E}}$ vs. LA. BG: Bulgaria; GR: Greece; HR: Croatia; PT: Portugal; HSA: Highspecification aggregates.

\subsection{AAV versus PSV}

Resistance to polishing is required for skid-resistant road surfaces. Aggregates with a rough micro texture, maintained by differential wear or continuous plucking, or by the presence of intergranular voids, have high resistance to polishing (high PSV). Abrasion resistance is also an important parameter that characterizes road-surfacing materials; it is affected by mineral hardness, grain size and orientation, and mineral weathering. The PSV and AAV data are listed in Table 3 and shown in Figure 3. The data were grouped according to material type and examined as such. The boundaries for high-specification aggregates (HSA, Thompson et al. 2004) are also given for comparison. The control stone (EN 1097-8) data in Table 3 (CS) are from the definitive study of West and Sibbick (1988) and the GeoTerra stock. Control stone is a fine- to medium-grained aphyric equigranular microgabbro, and the PSV and AAV are listed to aid the reader in the evaluation of the GeoTerra data reproducibility and bias.

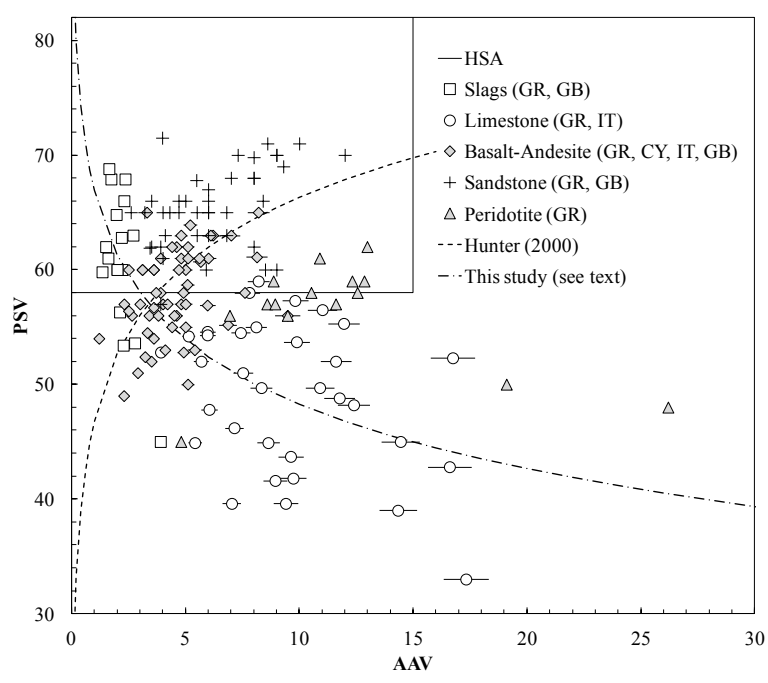

Figure 3 - AAV vs PSV. Aggregate sources are CY: Cyprus; GR: Greece; GB: Great Britain IT: Italy. HSA: High-specification aggregates.

XLVII, No $3-2076$ 
Two groups of aggregates and correlations are apparent in Figure 3. First, aggregates with moderately negative correlation such as limestones $(r=-0.49)$ and slags $(r=-0.63)$. Within this group, subgroups may exhibit stronger negative correlation than as a group; for example, Greek limestones with $r=-0.63$ and Italian limestones with $r=-0.68$. The second group comprises aggregates with variably moderate positive correlation such as basalt-andesite $(\mathrm{r}=0.39)$, sandstones $(r=0.44)$, and serpentine-poor peridotites $(r=0.79)$. The basalt-andesite group consists of crystalline rocks, and the sandstones are hard graywackes and gritstones. When serpentine-rich peridotites are included in the peridotites, the group as a whole exhibits weak negative correlation between PSV and AAV $(r=-0.26)$. Rigopoulos et al. (2012) noted the decrease in PSV and increase in AAV with increasing content of serpentine in peridotite samples. The dashed line in Figure 3 represents the equation PSV $=8.5 \times \ln$ AAV $+46.8\left(\mathrm{R}^{2}=0.76\right)$ of Hunter (2000) for igneous rocks and sandstones that exhibit positive PSV-AAV correlation-the data in Hunter (2000) are not shown or included in the analysis. A similar trend is produced by the equation(s) of Thompson et al. (2004) for such aggregates. The antithetic equation PSV $=-8.1 \times \ln$ AAV $+60.9\left(\mathrm{R}^{2}=0.56\right)$ (dot-dashed line in Figure 3$)$ of this study is for aggregates with negative PSV-AAV correlation. Apparently, such aggregates may not rejuvenate during service as maficintermediate volcanics and sandstones may do-polishing by traffic during the dry months and restoration by weathering during the rainy months. Therefore, in such cases, aggregates with high PSV and low AAV need to be selected as they will resist polishing and abrasion, e.g., steel slags.

Table 3 - Polishing Stone (PS) and Aggregate Abrasion (AA) values.

\begin{tabular}{|c|c|c|}
\hline PSV & $\boldsymbol{A} \boldsymbol{A} \boldsymbol{V}$ & Comments \\
\hline 67.9 & 2.35 & EAF slag \\
\hline 64.8 & 1.96 & $"$ \\
\hline 56.3 & 2.11 & $"$ \\
\hline 53.4 & 2.27 & $"$ \\
\hline 53.6 & 2.77 & $"$ \\
\hline 59.8 & 1.34 & $"$ \\
\hline 62.8 & 2.19 & EAF slag \\
\hline 67.9 & 1.73 & " \\
\hline 68.8 & 1.64 & $"$ \\
\hline 49.7 & 8.3 & Limestone (GR) \\
\hline 43.7 & 9.6 & “ \\
\hline 45.0 & 14.4 & “ \\
\hline 41.8 & 9.7 & “ \\
\hline 46.2 & 7.1 & “ \\
\hline 39.6 & 7.0 & “ \\
\hline 39.0 & 14.3 & “ \\
\hline 39.6 & 9.4 & “ \\
\hline 42.8 & 16.6 & “ \\
\hline 44.9 & 8.6 & “ \\
\hline 47.8 & 6.0 & “ \\
\hline 33.0 & 17.3 & “ \\
\hline 54.2 & 5.1 & “ \\
\hline 52.8 & 3.9 & “ \\
\hline 49.7 & 10.9 & “ \\
\hline 55.0 & 8.1 & “ \\
\hline 58.0 & 7.8 & “ \\
\hline 59.0 & 8.2 & “ \\
\hline 57.3 & 9.8 & “ \\
\hline
\end{tabular}

$\underline{\text { XLVII, No } 3-2077}$ 


\begin{tabular}{ccc}
\hline $\boldsymbol{P S} \boldsymbol{V}$ & $\boldsymbol{A} \boldsymbol{A} \boldsymbol{V}$ & Comments \\
\hline 52.0 & 5.7 & Siliceous limestone (GR) \\
54.3 & 6.0 & “ \\
53.7 & 9.9 & Limestone $(\mathrm{CY})$ \\
52 & 3.5 & CS (West \& Sibbick, 1988) \\
51 & 2.9 & CS (GeoTerra) \\
63.9 & 5.2 & Trachyte $(G R)$ \\
60.0 & 5.0 & Gabbro $(G R)$ \\
57.0 & 2.3 & Basalt $(G R)$ \\
56.0 & 4.6 & Andesite $(G R)$ \\
52.8 & 4.9 & Basalt (CY) \\
49.0 & 2.3 & “ \\
61.0 & 6.0 & Spillite $(G R)$ \\
57.0 & 3.0 & “ \\
\hline
\end{tabular}

CS: Control Stone. GR: Greece. CY: Cyprus. IT: Italy.

\section{Conclusions}

The FI-SI, $\mathrm{MD}_{\mathrm{S}}-\mathrm{MD}_{\mathrm{E}}, \mathrm{MD}_{\mathrm{E}}-\mathrm{LA}$, and PSV-AAV correlations were evaluated considering a large number of samples and different rock types. The FI-SI correlation is strongly positive and is well described by the 1:1 line; furthermore, the data suggest that hard materials with low FI and SI will contain a larger number of cubical and nonflaky grains. Strong positive correlation is also seen between $\mathrm{MD}_{\mathrm{S}}$ and $\mathrm{MD}_{\mathrm{E}}$, and $\mathrm{MD}_{\mathrm{E}}$ and $\mathrm{LA}$ that can be well fitted with the equation $\mathrm{LA}=4.95 \times$ $\mathrm{MD}_{\mathrm{E}}{ }^{0.61}\left(\mathrm{R}^{2}=0.69\right)$. As anticipated, hard aggregates have low MD and LA values. The PSV-AAV correlation divides aggregates into aggregates that exhibit high polishing for high abrasion resistance (high PSV-low AAV), such as limestone and slags, and into aggregates exhibiting high polishing for low abrasion resistance (high PSV-high AAV) that apparently characterizes sandstones and mafic-intermediate crystalline volcanics; peridotites belong to either PSV-AAV group depending on the content of low-hardness minerals.

\section{Acknowledgments}

I wish to thank the GeoTerra laboratory personnel for performing most of the tests reported here.

\section{References}

Bulevicius M., Petkevicius K., Cirba S., Zilioniene D., Oginskas R. and Bertuliene L. 2011. The influence of geometrical parameters on the strength of crushed stone used for the manufacture of asphalt mixtures, Environmental Engineering, Proc. $8^{\text {th }}$ International Conference, 1051-1056.

CEN (European Committee for Standardization) 2012. EN 933-3. Tests for geometrical properties of aggregates. Determination of particle shape. Flakiness index. Brussels.

CEN (European Committee for Standardization) 2008. EN 933-4. Tests for geometrical properties of aggregates. Determination of particle shape. Shape index. Brussels.

CEN (European Committee for Standardization) 2011. EN 1097-1. Tests for mechanical and physical properties of aggregates. Determination of the resistance to wear (micro-Deval). Brussels.

CEN (European Committee for Standardization) 2010. EN 1097-2. Tests for mechanical and physical properties of aggregates. Methods for the determination of resistance to fragmentation. Brussels.

CEN (European Committee for Standardization) 2009. EN 1097-8. Tests for mechanical and physical properties of aggregates. Determination of the polished stone value. Brussels.

XLVII, No $3-2078$ 
Cooley A.L., Huner M.S. and James R.H. 2002. Micro-Deval testing of aggregates in the SouthEast. National Center for Asphalt Technology. Report 02-09.

Cuelho E., Mokwa R. and Obert K. 2007. Comparative Analysis of Coarse Surfacing Aggregate Using Micro-Deval, L.A. Abrasion and Sodium Sulfate Soundness Tests, Report No. FHWA/MT-06-016/8117-27.

Cuelho E., Mokwa R., Obert K. and Miller A. 2008. Comparative analysis of micro-Deval, L.A. abrasion, and sulfate soundness tests. TRB 87th Annual Meeting: Conference Recordings, Washington D.C.

Hann D. 2009. Applicability of two different methods for determining particle shape, $R M Z-M a$ terials and Geoenvironment, Vol. 56, No. 1, 88-96.

Hunter R.N. 2000. Assessing aggregates, in Hunter and Edgar eds., Asphalts in Road Construction. London, UK: Thomas Telford. $568 \mathrm{pp}$.

Ioannou I., Petrou M.F., Fournari R., Andreou A. Hadjigeorgiou C., Tsikouras B., and Hatzipanagiotou K. 2010. Crushed limestone as an aggregate in concrete production: the Cyprus case in Limestone, in Smith, B.J., Gomez-Hera, M., Viles, H.A., and Cassar, J., eds., Limestone in the Built Environment: Present-Day Challenges for the Preservation of the Past: Geological Society, London, Special Publications, 331, 127-135.

Janoo V.C. 1998. Quantification of Shape, Angularity, and Surface Texture of Base Course Materials, US Army Corps of Engineers, Cold Regions Research \& Engineering Laboratory, Special Report 98-1, 29 pp.

Janoo V.C. and Korhonen C. 1999. Performance Testing of Hot-Mix Asphalt Aggregates, US Army Corps of Engineers, Cold Regions Research \& Engineering Laboratory, Special Report 99-20, 29 pp.

Kosiari S. 2007. Study of Northern Evia's Ultramafic Rocks as Skid-resistant Aggregates in Pavement Construction, Proc. $11^{\text {th }}$ Congress Geol. Soc. Greece, XXXVII, Athens.

Lancieri F., Losa M., and Marradi A. 2005. Resistance to polishing and mechanical properties of aggregates for asphalt concrete wearing courses. Proc. $3^{\text {rd }}$ International SIIV Congress, Vol. 4, 162-178, Bari, Italy.

Magerowski A., 2000. Controlling Crushing Costs And Particle Shape. International Center for Aggregates Research (ICAR), $8^{\text {th }}$ Annual Symposium Research Papers, B1-1.

Naidu G. and Adisheshu P.S. 2011. Influence of Coarse Aggregate Shape Factors on Bituminous Mixtures. International Journal of Engineering Research and Applications, Vol. 1, Issue 4, 2013-2024

Péturrson P., Bjarnasson G., and Torfason H. 2000. Testing of the aggregate bank with two CEN methods, $\mathrm{MD}_{\mathrm{E}}$ and FI. BUSL Report E-38, $17 \mathrm{pp}$.

Prapidis A., Doulis G. and Zotiadis V. 2005. Use of Slag in skid resistant asphalt mixes based on mechanical and environmental criteria, HELECO 05, Athens.

Pomonis P., Rigopoulos I., Tsikouras B. and Hatzipanagiotou K. 2007. Relationships between petrographic and physicomechanical properties of basic igneous rocks from the Pindos ophiolitic complex, NW Greece, Proc. $11^{\text {th }}$ Congress Geol. Soc. Greece, XXXVII, Athens, 947-958.

Reis Ferreira S.M., Correia A.G., Rogue A. and Cavalheiro A.M. 2010. Mechanical and environmental behavior of granular materials. Application to National Steel Slag, Semana de Engenharia. Guimaraes.

Rigopoulos I., Pomonis P., Tsikouras B. and Hatzipanagiotou K. 2006. Comparative study of dolerites from Pindos and Vourinos ophiolites for use as aggregates, Tech. Chron. Sci. J. $T C G$, I, No 3 .

Rigopoulos I., Pomonis P., Tsikouras B., Hatzipanagiotou K. and Stournaras K. 2008. A comparative study of the physicomechanical properties of mafic and ultramafic rocks from the Vourinos Ophiolite Complex (NW Greece), $1^{\text {st }}$ Greek Conference on Structural Materials and Elements, TGG. Athens

Rigopoulos I., Tsikouras B., Pomonis P. and. Hatzipanagiotou K. 2012. The impact of petrographic characteristics on the engineering properties of ultrabasic rocks from northern and

XLVII, No 3 - 2079 
central Greece, Quarterly Journal of Engineering Geology and Hydrogeology, 45, 423433.

Richardson D.N. 2009. Quick Test for Percent of Deleterious Material, Missouri University of Science and Technology. RI07-052, $169 \mathrm{pp}$.

Sofilić T., Rastovčan-Mioč A., Cosić M., Merle V., Mioč B. and Sofilić U. 2007. EAF steel slag application possibilities in Croatian Asphalt mixture production, $4^{\text {th }}$ International Conference on Molten Slags and Fluxes, Sendai, Japan, 481-486.

Thompson A., Burrows A., Flavin, D. and Walsh I. 2004. The Sustainable Use of High Specification Aggregates for Skid-Resistant Road Surfacing in England, Report to the Office of the Deputy Prime Minister and the Mineral Industry Research Organization. Published by Capita Symonds Ltd, East Grinstead.

Xirouchakis D. and Theodoropoulos A. 2009. Crushed limestone aggregates for concrete and masonry: Results from tests according to EN 12620, EN 13043, EN 13242, and EN 13139 standards, Proc. $16^{\text {th }}$ Concrete Conference, Cyprus.

Xirouchakis D. and Manolakou V. 2011. Properties of an EAF slag produced in Greece, a construction material for sustainable growth, Proc. $5^{\text {th }}$ International Conference for Bituminous Mixtures and Pavements. Thessaloniki, Greece.

Kalofotias A., Mavridou S. and Oikonomou N. 2011. Report on characteristics of natural aggregates, EU-LIFE+ Environment Policy and Governance LIFE 09 ENV/ $G R / 304$ "ROADTIRE," "Integration of end-of-life tires in the life cycle of road construction," ROADTIRE, Deliverable 4.1.1.

Uthus L., Hoff I. and Horvli I. 2005. Evaluation of grain shape characterization methods for unbound aggregates, Proc. $7^{\text {th }}$ International Conference on the Bearing Capacity of Roads, Railways and Airfields, Trondheim, Norway.

West G. and Sibbick R.G. 1988. Petrographical comparison of old and new control stones for the accelerated polishing test, Quarterly Journal of Engineering Geology, London, Vol. 21, 375-378. 